Article

\title{
Evaluating the Scenic Beauty of Individual Trees: A Case Study Using a Nonlinear Model for a Pinus Tabulaeformis Scenic Forest in Beijing, China
}

\section{Bin Mao ${ }^{\dagger}$, Lan Gong ${ }^{\dagger}$ and Chengyang $\mathrm{Xu}$ *}

Key Laboratory for Silviculture and Conservation of Ministry of Education, Beijing Forestry University, Beijing 100083, China; E-Mails: maobin3322@126.com (B.M);

langong_bjfu@163.com (L.G.)

$\dagger$ These authors contributed equally to this work.

* Author to whom correspondence should be addressed; E-Mail: cyxu@bifu.edu.cn;

Tel.: +86-010-6233-7082; Fax: +86-010-6233-7082.

Academic Editor: Eric J. Jokela

Received: 2 March 2015 / Accepted: 20 May 2015 / Published: 1 June 2015

\begin{abstract}
The relationship between scenic beauty grade and measured tree indicators was studied through evaluation of 427 photos of individual Pinus tabulaeformis trees by using the scenic beauty estimation (SBE) method. Thirteen indices to reflect trunk, crown and stem-to-canopy ratios of individual trees were evaluated by invited students. Results showed that students preferred large diameters at breast height, full canopies and straight stems or some trees with minor crook stems. Tree height had a minor contribution to individual tree quality. Correlation analysis and factor analysis were employed to select indices and to integrate them into a comprehensive index. The stepwise method of nonlinear model incorporation of four comprehensive indices - tree crown form, stem-crown coordination, tree growth and stem for-were proven valuable in order to evaluate the scenic beauty of individual trees.
\end{abstract}

Keywords: Pinus tabulaeformis; scenic forest; scenic beauty of individual trees; nonlinear model 


\section{Introduction}

Modern urbanization requires forests to serve more functions than just timber production and ecological conservation. Accordingly, the core objective of urban forest management has now been upgraded to include the creation of a more beautiful forest landscape for attracting outdoor recreation activities [1]. In order to achieve the scientific management of scenic forests, their beauty should be evaluated properly and precisely [2].

Generally, scenic forests are evaluated through several indices, which provide an assessment method to identify what types of forests are more attractive for most people. Scenic beauty estimation (SBE), as one of the most widely and effectively used methods, was popularized over the last several decades [3]. By means of SBE, different photographic slides of landscapes could be rated on a numeric scale from 1 to 10 . Thereafter, the multiple regression linear model was used to evaluate the forests according to the preferred scenic physical characteristics at the landscape scale [4], near-view-forest [5-7] and isolated tree scenery [8]. People's evaluation of scenic beauty is subjective, which is difficult to express with a linear relationship [7,9]. Therefore, a nonlinear model was applied to the studies of Analytic Hierarchy Process (AHP) [1] and neural networks [7,10]. So far, evidence is insufficient to supply essential evaluation of scenic beauty of isolated trees through nonlinear regression. In fact, for scenic forest landscapes, tree quality is very important for whole forest management because some metrics, such as tree size [11], stem-to-canopy ratio [8], crown [12] and trunk [13] could remarkably affect the human preferences. These metrics could be obtained by monitoring the management of thinning according to human preferences. Existent studies have documented improvement of the perceived scenic beauty of forest landscapes through many thinning regimes [14-18].There is no reference available for logging when the construction of landscape beauty is considered in P. tabulaeformis stand. Generally, morphological characteristics of individual trees can be classified into several grades and different grades reflect various management strategies [12]. However, this information is still insufficient for current understanding regarding the grade evaluation of scenic beauty for an individual tree.

China's capital city of Beijing is undergoing rapid urbanization and has many typical urban characteristics similar to other Chinese cities. In Beijing, mountainous scenic forests are mainly dominated by $P$. tabulaeformis [19], which accounts for $19.6 \%$ of all tree species. However, most P. tabulaeformis forests are at young or mid-maturation stages (44.4\% and $31.1 \%$, respectively), and their scenic attributes and recreational function are hindered by their simple structure, low species diversity, poor growth status, and over high density. These shortcomings have been identified to impact the quality of scenic forests in Beijing [12]. Therefore, individual tree quality needs to be considered by urban planning decision makers to improve the scenic beauty in Beijing and other similar cities.

This study reports the results of an investigation undertaken in Beijing. The tree characteristic indicators and scenic evaluations were combined and analyzed for the construction of an "individual tree evaluation model" by selecting indicators that significantly influenced scenic beauty. The study was based on the following hypotheses: (1) the scenic quality of individual trees could be indicated by regressed indicators; (2) a matrix of comprehensive indices could be built according to the correlation between indicators that are not fully independent; and (3) nonlinear models based on regression from the matrix could perform better than a linear one. 


\section{Material and Methods}

\subsection{Description of the Study Area}

The study was conducted in experimental Xishan forest park, which is located on Xiaoxishan mountain $\left(116^{\circ} 28^{\prime} \mathrm{E}, 39^{\circ} 34^{\prime} \mathrm{N}\right)$ in Beijing, in a temperate continental monsoon climate zone with a mean annual temperature of $11.6^{\circ} \mathrm{C}$. It has an average annual precipitation of $630 \mathrm{~mm}$ and an average relative humidity of $66 \%$. The research site was low-altitude rocky mountain (average elevation ranges from 200 to $400 \mathrm{~m}$ ), where the average soil layer thickness is 30 to $50 \mathrm{~cm}$. Soil components were determined to be gravel. The total area of the research region is 5949 ha, and forest accounts for $92.32 \%$. The dominant tree species is $P$. tabulaeformis, and Platycladus orientalis also contributes to the dominant tree community. Other tree species, such as Robinia pseudoacacia, Morus mongolica, and Koelreuteria paniculata, are sporadic, while main shrub species, including Vitex negundo, Grewia biloba and herbaceous plants, including Oplismenus undulatifolius, Carex duriuscula, etc., were evenly distributed.

\subsection{Sampling Area Selection}

Thirteen sample plots with total area of $5200 \mathrm{~m}^{2}$ P. tabulaeformis stand were chosen to survey for the present study (Table 1). Each sample plot was $20 \mathrm{~m} \times 20 \mathrm{~m}$, and all sample plots presented typical landforms of the whole stand. The distribution and growth status of forest trees, shrubs, and herbaceous plants in the sample plots were firstly surveyed to identify the initial conditions of the stand before the study was commenced. A total of thirteen survey samples and 554 individual P. tabulaeformis trees in the forest were then investigated. 
Table 1. Stand description and attributes of main trees within plots.

\begin{tabular}{|c|c|c|c|c|c|c|c|c|}
\hline Forest Stand Types & $\begin{array}{l}\text { Number of } \\
\text { Samples }\end{array}$ & $\begin{array}{c}\text { Tree } \\
\text { Numbers Per } \\
\text { ha }\left(\text { Tree.ha }^{-1}\right)\end{array}$ & $\begin{array}{c}\text { Number of } \\
\text { Individual } \\
\text { Trees } \\
\end{array}$ & $\begin{array}{c}\text { Average Tree } \\
\text { Height (m) }\end{array}$ & $\begin{array}{c}\text { Average Diameter at } \\
\text { Breast Height }(\mathrm{cm})\end{array}$ & $\begin{array}{l}\text { Under Branch } \\
\text { Height (h) }\end{array}$ & $\begin{array}{c}\text { Coverage } \\
\text { Rate of } \\
\text { Shrubs (\%) } \\
\end{array}$ & $\begin{array}{l}\text { Visibility in } \\
\text { Forest (m) }\end{array}$ \\
\hline $\begin{array}{l}\text { In-forest tidy, forest } \\
\text { undergrowth rich, pruning }\end{array}$ & 5 & 730 & 200 & $6.0-9.1$ & 16.7 & $1 / 3-2 / 3 \mathrm{H}$ & $0.7-0.9$ & $25-30$ \\
\hline $\begin{array}{l}\text { In-forest tidy forest, } \\
\text { undergrowth less, pruning }\end{array}$ & 3 & 1200 & 200 & $5.3-10.1$ & 11.3 & $1 / 3-2 / 3 \mathrm{H}$ & $0-0.6$ & $15-20$ \\
\hline $\begin{array}{l}\text { In-forest not tidy, forest } \\
\text { undergrowth rich, no pruning }\end{array}$ & 3 & 789 & 160 & $7.0-9.1$ & 14.2 & $1 / 4-1 / 3 \mathrm{H}$ & $0.7-0.9$ & $5-7$ \\
\hline $\begin{array}{c}\text { In-forest not tidy, forest } \\
\text { undergrowth less, no pruning }\end{array}$ & 2 & 1000 & 150 & $6.0-10.1$ & 12.8 & $1 / 4-1 / 3 \mathrm{H}$ & $0.1-0.6$ & $6-8$ \\
\hline
\end{tabular}

Forest undergrowth are the plants in a forest which just reach a relatively low height compared with P. tabulaeformis, such as grasses and shrubs. 


\subsection{Selection for Measuring Tree Indices}

Three categories representative of trunk, crown and stem-to-canopy ratio were defined. In each category, different indices were selected to reflect the characteristic (Table 2).

Table 2. The abbreviations and descriptions of individual tree indices.

\begin{tabular}{ccc}
\hline Category & Abbreviation & Indicator \\
\hline \multirow{3}{*}{ isolated tree trunk } & AID & annual average increment of diameter \\
& SLD & stem lean degree \\
& SSD & stem straight degree \\
\hline & AIC & annual average increment of crown \\
& CV & crown volume \\
isolated tree crown & CED & crown width/tree height ratio \\
& CRD & crown width/crown height ratio \\
& CR & crown height/tree height ratio \\
& CSD & crown symmetry degree \\
& RDCL & dead crown/crown ratio \\
\hline stem-to-canopy ratio for isolated tree & RCWD & crown width/diameter ratio \\
& RDH & diameter/tree height ratio \\
& AIH & annual average increment of tree height
\end{tabular}

Where, $S L D=\mathrm{L}_{a} / \mathrm{L}_{b}, \mathrm{~L}_{\mathrm{a}}$ is vertical trunk height, $\mathrm{L}_{\mathrm{b}}$ is actual length of the trunk; $\mathrm{SSD}=\mathrm{L}_{\mathrm{s}} / \mathrm{L}_{\mathrm{c}}, \mathrm{L}_{\mathrm{S}}$ is the straight trunk length, $\mathrm{L}_{\mathrm{C}}$ is the curved trunk length; $\mathrm{CSD}=\left(\mathrm{C}_{\mathrm{w}} / \mathrm{C}_{\mathrm{e}}+\mathrm{C}_{\mathrm{s}} / \mathrm{C}_{\mathrm{n}}\right) / 2, \mathrm{C}_{\mathrm{w}}, \mathrm{C}_{\mathrm{e}}, \mathrm{C}_{\mathrm{s}}, \mathrm{C}_{\mathrm{n}}$ are the crown length in north-, south-, east- and west-direction.

\subsection{Photography}

To make the trait of an individual tree clear, considerable care was taken during photography. All pictures were collected with a $70 \mathrm{~mm}$ focal length in the time with bright lighting between 9 am and $3 \mathrm{pm}$. To guarantee the key characteristics were evident in the picture, all distracting elements (e.g., grass undergrowth) were cropped out.

\subsection{Evaluation of Scenic Beauty Estimation Value}

Fifty-five persons who were studying different professions (e.g., forestry, ecology, landscape architecture and soil and water conservation) at Beijing Forestry University and five persons who were working at various businesses were invited to provide evaluation. First, the seven grades of beauty classification were introduced to all evaluators. All participants could evaluate a picture with scores of -3 , $-2,-1,0,1,2,3$, which correspond to "do not like at all”, "do not like very much", "do not like", "do not care", "like a little", "like", and "like it very much", respectively. Second, a quick glance at the

pictures was provided to familiarize evaluators with the overall landscape quality. Thirdly, 427 pictures were shown to evaluators for grading at an interval of $8 \mathrm{~s}$. In total, all pictures were evaluated by 60 participants, results were summarized to provide a basis for further analysis. 


\section{Data Processing and Analysis}

The data were analyzed using the Statistical Package for Social Sciences and Excel. Data analysis is described below.

(1) The SBE value was sorted from large to small. The individual tree quality was classified into five grades: Excellent (Grade I), very good (Grade II), average (Grade W), below average (Grade IV) and failing (Grade V) (Table 3). One-way ANOVA was employed to analyze the relationship between the indicator and scenic beauty significance of difference at a level of 0.05 .

Table 3. Calculation for lower limit value and upper limit value for each grade (based on Zhang [12]).

\begin{tabular}{ccc}
\hline Grade & Lower limit value & Upper limit value \\
\hline I & (MaxSBE-MinSBE) $\times 80 \%+$ MinSBE & MaxSBE \\
II & (MaxSBE-MinSBE) $\times 60 \%+$ MinSBE & (MaxSBE-MinSBE) $\times 80 \%+$ MinSBE \\
W & (MaxSBE-MinSBE) $\times 40 \%+$ MinSBE & (MaxSBE-MinSBE) $\times 60 \%+$ MinSBE \\
IV & (MaxSBE-MinSBE) $\times 20 \%+$ MinSBE & (MaxSBE-MinSBE) $\times 40 \%+$ MinSBE \\
V & MinSBE & (MaxSBE-MinSBE) $\times 20 \%+$ MinSBE \\
\hline
\end{tabular}

(2) Spearman correlation analysis was performed between the SBE value and 13 indicators. This result was then used to eliminate some indicators.

(3) Factor analysis was adopted in this study to classify the indices which passed the previous screening into several groups. Classifying indicators and definitions based on rotating component matrices were implemented, according to the factor score to recount classification group. However, because the traditional factor score calculation was relatively long, simplified factor score calculation steps were utilized in this paper and described below.

(3.1) All indicators need to use standardized processing following Equation (1):

$$
B_{i}=\frac{X_{i}-X_{\min }}{X_{\max }-X_{\min }}
$$

where $\mathrm{B}_{i}$ is the standardization value, $\mathrm{X}_{i}$ is the $i$ th indicator for and isolated tree, $i=1,2,3 \ldots n, \mathrm{X}_{\min }$ and $\mathrm{X}_{\max }$ are the minimum and maximum values for index $\mathrm{X}_{i}$, respectively.

(3.2) Indicator weight coefficients from subordinate factors were then determined by (2):

$$
Q_{i}=\frac{\sum X_{i}}{\sum X_{i}+\sum X_{n}}
$$

where $\mathrm{Q}_{i}$ is the weight coefficient for the $i$ th indicator.

(3.3) The basis of indicator weight and the correlation between the index and factor can be expressed by (3):

$$
\mathrm{Ua}=X_{i} \times Q_{i} \pm X_{n} \times Q_{n}
$$

where $\mathrm{U}$ is index, $\mathrm{a}$ is number of index, $\mathrm{a}=1,2 \ldots n$.

(3.4) In previous studies, linear models and some nonlinear models such as AHP [12] were introduced to evaluate scenic beauty for single trees. Quadratic polynomials were only used to establish landscape [22] but not single trees' evaluations. It is meaningful to evaluate scenic beauty for individual trees with different models. Ua and SBE were taken as the explanatory variable and the response variable, respectively, to establish a linear model of multiple linear regression and multiple linear stepwise 
regression and a nonlinear model of quadratic polynomial regression and quadratic polynomial stepwise regression. Whether to proceed was determined according to the correlation coefficient $R^{2}$ of each method. All models were based on a removal probability for $F$ of 0.10 and an entry probability of 0.05 .

\section{Results}

\subsection{The Relationship Between the Quality Traits of Individual Trees and SBE Grades}

Analysis of variance indicated that most relationships between indices and SBE grades were significant or very significant at the 0.05 level, except for indices including crown symmetry degree (CSD), crown width/diameter ratio (RDCW) and stem lean degree (SLD) (Table 4). Hence, these indices were all eliminated. In addition, the multiple comparisons suggest that most indices changed linearly with SBE grade, but annual average increment of tree height (AIH), diameter/tree height ratio (RDH) and stem straight degree (SSD) parameters changed nonlinearly with change of SBE grades. The fact that annual average increment of diameter (AID), annual average increment of crown (AIC), crown volume $(\mathrm{CV})$, crown width/tree height ratio (CED), and crown height/tree height ratio (CR) parameters increased with the increase of SBE grade suggests that these values' increases have a strong promotional effect to quality of landscape for individual trees. The crown width/crown height ratio (CRD) and dead crown/crown ratio (RDCL) parameters reduction with the increase of SBE grade suggests these values' increases have a strong reduction effect on the quality of landscape individual trees, but the annual average increment of tree height (AIH) and stem straight degree (SSD) parameters having the maximum quadratic curve trend change with the increasing of SBE grade suggests that raising or lowering these indicators has a negative impact on the quality of landscape individual trees. However, diameter/tree height ratio $(\mathrm{RDH})$ parameter having minimum quadratic curve trend change with the increasing of SBE grade suggests that extreme changes value can effectively improve the quality of landscape individual trees.

Table 4. Relationships between quality traits and scenic beauty estimation (SBE) grades for individual trees.

\begin{tabular}{|c|c|c|c|c|c|c|c|}
\hline \multirow{2}{*}{ indices } & \multicolumn{5}{|c|}{ SBE grade } & \multirow{2}{*}{$F$} & \multirow{2}{*}{$P$} \\
\hline & $\mathbf{I}$ & II & III & IV & $\mathbf{V}$ & & \\
\hline $\mathrm{AIH}$ & $0.059 a \pm 0.034$ & $0.066 \mathrm{~b} \pm 0.034$ & $0.076 c \pm 0.039$ & $0.075 c \pm 0.042$ & $0.069 \mathrm{~d} \pm 0.031$ & 3.243 & 0.012 \\
\hline AID & $0.503 \mathrm{a} \pm 0.02$ & $0.415 b \pm 0.033$ & $0.345 c \pm 0.028$ & $0.290 \mathrm{~d} \pm 0.021$ & $0.248 \mathrm{e} \pm 0.019$ & 440.407 & $<0.001$ \\
\hline AIC & $0.058 \mathrm{a} \pm 0.036$ & $0.056 \mathrm{a} \pm 0.027$ & $0.049 b \pm 0.023$ & $0.041 \mathrm{c} \pm 0.014$ & $0.034 c \pm 0.009$ & 9.755 & $<0.001$ \\
\hline $\mathrm{CV}$ & $11.392 \mathrm{a} \pm 6.33$ & $9.905 b \pm 6.464$ & $8.660 \mathrm{c} \pm 7.334$ & $5.961 \mathrm{~d} \pm 5.936$ & $7.375 d \pm 7.332$ & 7.926 & $<0.001$ \\
\hline CRD & $1.520 \mathrm{a} \pm 0.502$ & $1.54 \mathrm{a} \pm 0.578$ & $1.603 a \pm 0.667$ & $1.825 b \pm 1.065$ & $1.765 b \pm 0.802$ & 2.933 & 0.020 \\
\hline CED & $0.637 \mathrm{a} \pm 0.136$ & $0.580 \mathrm{~b} \pm 0.127$ & $0.55 \mathrm{c} 1 \pm 0.144$ & $0.508 \mathrm{~d} \pm 0.147$ & $0.518 \mathrm{~d} \pm 0.147$ & 9.076 & $<0.001$ \\
\hline CSD & $1.283 a \pm 0.630$ & $1.308 \mathrm{a} \pm 0.681$ & $1.262 \mathrm{a} \pm 0.564$ & $1.147 \mathrm{a} \pm 0.543$ & $1.092 \mathrm{a} \pm 0.364$ & 2.04 & 0.088 \\
\hline $\mathrm{CR}$ & $0.443 a \pm 0.120$ & $0.410 \mathrm{ab} \pm 0.133$ & $0.394 b \pm 0.165$ & $0.345 \mathrm{c} \pm 0.159$ & $0.358 \mathrm{c} \pm 0.179$ & 4.825 & 0.001 \\
\hline $\mathrm{RDH}$ & $0.030 \mathrm{a} \pm 0.006$ & $0.028 \mathrm{a} \pm 0.006$ & $0.026 \mathrm{~b} \pm 0.005$ & $0.025 b \pm 0.005$ & $0.027 \mathrm{c} \pm 0.005$ & 10.998 & $<0.001$ \\
\hline
\end{tabular}


Table 4. Cont.

\begin{tabular}{|c|c|c|c|c|c|c|c|}
\hline \multirow{2}{*}{ indices } & \multicolumn{5}{|c|}{ SBE grade } & \multirow{2}{*}{$F$} & \multirow{2}{*}{$P$} \\
\hline & I & II & III & IV & $\mathbf{V}$ & & \\
\hline RDCL & $0.053 a \pm 0.039$ & $0.222 \mathrm{a} \pm 0.403$ & $0.401 b \pm 0.570$ & $0.598 \mathrm{c} \pm 0.700$ & $1.061 \mathrm{~d} \pm 0.900$ & 15.791 & $<0.001$ \\
\hline RCWD & $0.002 \mathrm{a} \pm 0.051$ & $0.002 \mathrm{a} \pm 0.048$ & $0.002 \mathrm{a} \pm 0.047$ & $0.002 \mathrm{a} \pm 0.032$ & $0.002 \mathrm{a} \pm 0.030$ & 1.802 & 0.127 \\
\hline SLD & $0.859 \mathrm{a} \pm 0.309$ & $0.870 \mathrm{a} \pm 0.305$ & $0.922 b \pm 0.232$ & $0.950 \mathrm{~b} \pm 0.189$ & $0.948 b \pm 0.201$ & 3.439 & 0.090 \\
\hline SSD & $0.008 \mathrm{a} \pm 0.061$ & $0.093 b \pm 0.187$ & $0.085 b \pm 0.182$ & $0.102 b \pm 0.178$ & $0.070 \mathrm{c} \pm 0.193$ & 3.771 & 0.005 \\
\hline
\end{tabular}

Note: Different lower case letters indicate significant differences at the 0.05 level. AIH is annual average increment of tree height, AID is annual average increment of diameter, AIC is annual average increment of crown, $\mathrm{CV}$ is crown volume, $\mathrm{CRD}$ is crown width/crown height ratio, $\mathrm{CED}$ is crown width/tree height ratio, $\mathrm{CSD}$ is crown symmetry degree, $\mathrm{CR}$ is crown height/tree height ratio, $\mathrm{RDH}$ is diameter/tree height ratio, $\mathrm{RDCL}$ is dead crown/crown ratio, RCWD is crown width/diameter ratio, SLD is stem lean degree, SSD is stem straight degree.

\subsection{Relationships between Indicator and Scenic Beauty Value}

Except for crown width/crown height ratio (CRD), correlations between the rest parameter and SBE value were all found to be significant at the level of $p<0.01$ (Table 5). In this study, only those parameters have extremely significant correlations $(p<0.01)$ with SBE value were involved in factor analysis. In this sense, parameters of crown width/ crown height ratio (CRD) were eliminated as indicators of scenic beauty.

The absolute value of the correlation coefficient can be used as a standard to measure the influence of indicators on SBE value. From large effects to small effects, the indicators are ordered as follows: Annual average increment of diameter $($ AID) $>$ dead crown/crown ratio (RDCL) $>$ annual average increment of crown $(\mathrm{AIC})>$ crown volume $(\mathrm{CV})>$ crown width/tree height ratio $(\mathrm{CED})>$ crown height/tree height ratio $(\mathrm{CR})>$ stem straight degree $(\mathrm{SSD})>$ diameter/tree height ratio $(\mathrm{RDH})>$ annual average increment of tree height (AIH).

There were various correlations between different indices for isolated trees (Table 4). Firstly, there was a positive correlation between crown volume $(\mathrm{CV})$ and crown height/tree height ratio $(\mathrm{CR})$, while a negative correlation was observed between dead crown/crown ratio (RDCL) and both crown volume (CV) and crown height/tree height ratio (CR). This might be caused by the increasing canopy area; with the development of live branches, the proportion of dead branches decreases. Secondly, annual average increment of tree height (AIH) has a negative correlation with crown width/tree height ratio (CED) and diameter/tree height ratio $(\mathrm{RDH})$. The value of crown width/tree height ratio and diameter/tree height ratio was obtained from the crown and diameter at breast height (DBH) compared with tree height, thus the values of crown width/tree height ratio and diameter/tree height ratio (RDH) were affected by tree height. Thirdly, a positive correlation was also observed for annual average increment of diameter (AID) and annual average increment of crown (AIC), which means that the crown shows a positive linear trend with changing tree diameter. No more correlations between stem straight degree (SSD) and other indices are observed. There was no evidence to show that bending trees were influenced by the crown size or tree diameter. High correlations suggest that there may be overlap between indicators and one may be redundant for analysis. Hence, factor analysis was used to integrate them into a comprehensive index in order to decrease the amount of variables in the model. 
Table 5. Significance correlations between indicators of individual trees.

\begin{tabular}{|c|c|c|c|c|c|c|c|c|c|c|c|}
\hline & SBE & $\mathrm{CV}$ & CED & RDH & AIH & AID & AIC & CR & SSD & RDCL & CRD \\
\hline \multicolumn{12}{|l|}{ SBE } \\
\hline $\mathrm{CV}$ & $0.237 * *$ & & & & & & & & & & \\
\hline CED & $0.227 * *$ & $0.429 * *$ & & & & & & & & & \\
\hline RDH & $-0.121 * *$ & $0.100 *$ & $0.607 * *$ & & & & & & & & \\
\hline AIH & $-0.11 * *$ & 0.068 & $-0.576 * *$ & $-0.816 * *$ & & & & & & & \\
\hline AID & $0.900 * *$ & $0.195 * *$ & $0.206 * *$ & $0.214 * *$ & $0.099 *$ & & & & & & \\
\hline AIC & $0.267 * *$ & $0.120 * *$ & 0.068 & $0.095 *$ & 0.004 & $0.334 * *$ & & & & & \\
\hline CR & $0.182 * *$ & $0.622 * *$ & $0.390 * *$ & $0.156 * *$ & -0.073 & $0.143 * *$ & 0.095 & & & & \\
\hline SSD & $-0.134 * *$ & 0.022 & 0.013 & 0.040 & -0.020 & -0.070 & -0.068 & -0.028 & & & \\
\hline RDCL & $-0.343 * *$ & $-0.358 * *$ & $-0.383 * *$ & $-0.198 * *$ & $0.151 * *$ & $-0.295 * *$ & $-0.107 *$ & $-0.565 * *$ & -0.002 & & \\
\hline CRD & $0.090 *$ & -0.051 & 0.034 & -0.032 & -0.064 & $0.121 * *$ & 0.021 & 0.043 & -0.034 & -0.071 & \\
\hline
\end{tabular}

$*$ denotes $p<0.05$ and ** denotes $p<0.01$; SBE is SBE value; CV is crown volume; CED is crown width / tree height ratio; $\mathrm{RDH}$ is diameter / tree height ratio; AIH is annual average increment of tree height; AID is annual average increment of diameter; AIC is annual average increment of crown; CR is crown height/tree height ratio SSD is stem straight degree; RDCL is dead crown /crown ratio; CRD is crown width / crown height ratio. 


\subsection{Established Quality Traits of Isolated Trees with an Index Equation}

Results from factor analysis showed that the contribution rates for 4 factors were $25.7 \%, 25 \%, 15 \%$, and $11.84 \%$, respectively. Together, the four factors account for $77.54 \%$ of the total variance (Table 6 ). The results from the rotated component matrix showed that there was a positive correlation between Factor 1 and diameter/tree height ratio $(r=0.93)$ and crown width/tree height ratio $(r=0.72)$, but the correlation was negative between Factor 1 and annual average increment of tree height $(r=-0.94)$. Factor 1 reflected the coordination degree between the canopy and the trunk; hence it was defined as the stem-crown harmony index, and expressed as $U_{1}$. The relationship between Factor 2 and parameters crown volume $(r=0.83)$ and crown height/tree height ratio $(r=0.89)$ presented positive correlations, while Factor 2 and dead crown/crown ratio $(r=-0.70)$ showed a negative correlation. Factor 2 was defined as the crown shape index and is expressed as $U_{2}$. The relationship between Factor 3 and annual average increment of diameter $(r=0.76)$ and annual average increment of crown $(r=0.85)$ showed positive correlations. Because Factor 3 described tree growth, it was defined as growth index, expressed as $\mathrm{U}_{3}$. The relationship between Factor 4 and stem straight degree $(r=0.96)$ presented a positive correlation. Because Factor 4 quantified trunk straightness, it was defined as the stem shape index and expressed as $\mathrm{U}_{4}$.

Table 6. Rotated component matrix of 4 factors for 9 indices.

\begin{tabular}{ccccc}
\hline Index & Factor 1 & Factor 2 & Factor 3 & Factor 4 \\
\hline diameter/tree height ratio & 0.93 & 0.09 & 0.12 & -0.02 \\
annual average increment of tree height & -0.94 & 0.06 & 0.01 & 0.05 \\
annual average increment of diameter & 0.13 & 0.18 & 0.76 & 0.18 \\
annual average increment of crown & -0.01 & 0.04 & 0.85 & 0.11 \\
stem straight degree & 0.03 & -0.04 & -0.03 & 0.96 \\
dead crown/crown ratio & 0.16 & -0.70 & -0.15 & 0.29 \\
crown volume & -0.01 & 0.83 & 0.11 & 0.11 \\
crown width/tree height ratio & 0.72 & 0.49 & 0.05 & 0.01 \\
crown height/tree height ratio & 0.09 & 0.89 & 0.03 & 0.01 \\
Cumulative factor contribution (\%) & 25.71 & 50.07 & 65.70 & 77.54 \\
\hline
\end{tabular}

According to the simplified factor calculation method in this paper, the index Equations are (4)-(7) as follows:

$$
\begin{gathered}
\mathrm{U}_{1}=0.33 \times \mathrm{RDH}+0.39 \times \mathrm{CED}-0.27 \times \mathrm{AIH} \\
\mathrm{U}_{2}=0.33 \times \mathrm{CV}+0.57 \times \mathrm{CR}-0.109 \times \mathrm{RDCL} \\
\mathrm{U}_{3}=0.48 \times \mathrm{AID}+0.52 \times \mathrm{AIC} \\
\mathrm{U}_{4}=\mathrm{SSD}
\end{gathered}
$$

Where, $\mathrm{CV}$ is crown volume; $\mathrm{CED}$ is crown width/ tree height ratio; $\mathrm{RDH}$ is diameter/tree height ratio; AIH is annual average increment of tree height; AID is annual average increment of diameter; AIC is annual average increment of crown; $\mathrm{CR}$ is crown height/tree height ratio; SSD is stem straight degree; RDCL is dead crown / crown ratio. 


\subsection{Model of Quality Traits of Individual Trees}

The model and all explanatory variables were significant or very significant at the 0.05 level (Table 7). Based on comparison of $R^{2}$ from these models, the precision in the nonlinear model is higher than that of the linear model. $R^{2}$ value in multiple linear stepwise regression $(0.63)$ is higher than it in multiple linear regression (0.60). The highest $R^{2}$ value $(0.66$, same in quadratic polynomial regression and quadratic polynomial stepwise regression) were obtained in the nonlinear model.

Table 7. Regression descriptions of independent variable number, model formula regression, and formula fitting status for quality traits of individual tree indices.

\begin{tabular}{ccccc}
\hline Model Type & Model Formula & $\boldsymbol{R}^{2}$ & $\boldsymbol{F}$ & $\boldsymbol{p}$ \\
\hline $\begin{array}{c}\text { Multiple linear } \\
\text { regression } \\
\text { Multiple linear } \\
\text { stepwise regression }\end{array}$ & $\mathrm{SBE}=27.47+18 \mathrm{U}_{1}+27.95 \mathrm{U}_{2}+150.39 \mathrm{U}_{3}-4.06 \mathrm{U}_{4}$ & 0.60 & 180.25 & 0.001 \\
& $\mathrm{SBE}=26.98+18.02 \mathrm{U}_{1}+27.71 \mathrm{U}_{2}+150.8 \mathrm{U}_{3}$ & 0.63 & 240.21 & $<0.001$ \\
Quadratic polynomial & $\mathrm{SBE}=19.45+40.41 \mathrm{U}_{1}+9.21 \mathrm{U}_{2}+206.56 \mathrm{U}_{3}-3.18 \mathrm{U}_{4}-$ & & & \\
regression & $\begin{array}{c}68 . \mathrm{U}_{1}^{2}-108.45 \mathrm{U}_{2}^{2}-88.58 \mathrm{U}_{3}^{2}-3.12 \mathrm{U}_{4}^{2}+126.73 \mathrm{U}_{1} \mathrm{U}_{2}- \\
5.01 \mathrm{U}_{1} \mathrm{U}_{3}+22.97 \mathrm{U}_{1} \mathrm{U}_{4}+67.57 \mathrm{U}_{2} \mathrm{U}_{3}-11.09 \mathrm{U}_{2} \mathrm{U}_{4}-\end{array}$ & 0.66 & 58.29 & $<0.001$ \\
& $13.66 \mathrm{U}_{3} \mathrm{U}_{4}$ & & & \\
$\begin{array}{c}\text { Quadratic polynomial } \\
\text { stepwise regression }\end{array}$ & $\mathrm{SBE}=19.84+42.98 \mathrm{U}_{1}+206.43 \mathrm{U}_{3}-72.22 \mathrm{U}_{1}{ }^{2}-103.48 \mathrm{U}_{2}^{2}$ \\
& $-93.63 \mathrm{U}_{3}^{2}+76.81 \mathrm{U}_{2} \mathrm{U}_{3}-14.94 \mathrm{U}_{3} \mathrm{U}_{4}+133.22 \mathrm{U}_{1} \mathrm{U}_{2}$ & 0.66 & 103.13 & 0.001 \\
\hline
\end{tabular}

SBE represents scenic beauty value; $U_{1}$ represents stem-crown harmony index; $\mathrm{U}_{2}$ represents crown shape index; $\mathrm{U}_{3}$ represents growth index; $\mathrm{U}_{4}$ represents stem shape index; and $R^{2}$ represents coefficient of determination.

The theoretical values of model in theory are values for growth index, crown shape index, stem-crown harmony index and stem shape index, which were equivalent to the maximum SBE value (Figure 1). The relationship between one comprehensive index and the SBE value can be obtained through setting the other three comprehensive indices to be their theoretical values. Results showed that: (1) with the increasing of stem-crown harmony index, crown shape index, and growth index, SBE increased rapidly; (2) while these three comprehensive indices reached their theoretical values of $0.85,0.7,0.96$, SBE reached the optimum value of 196.22 in theory; (3) while stem-crown harmony index and crown shape index were more than their theoretical value, SBE decreased dramatically; (4) while growth index was over its theoretical value, SBE decreased slowly; (5) while stem shape index was equal to 0, SBE reached its optimum value, with the increasing value of this index, SBE decreased linearly. 

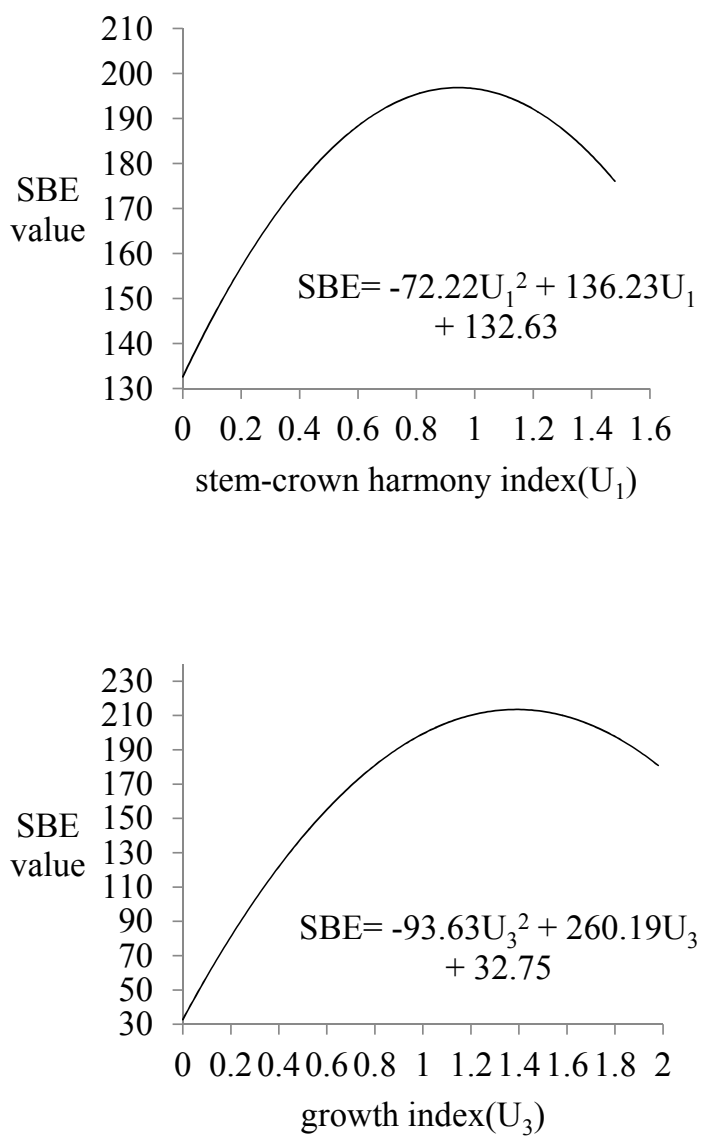
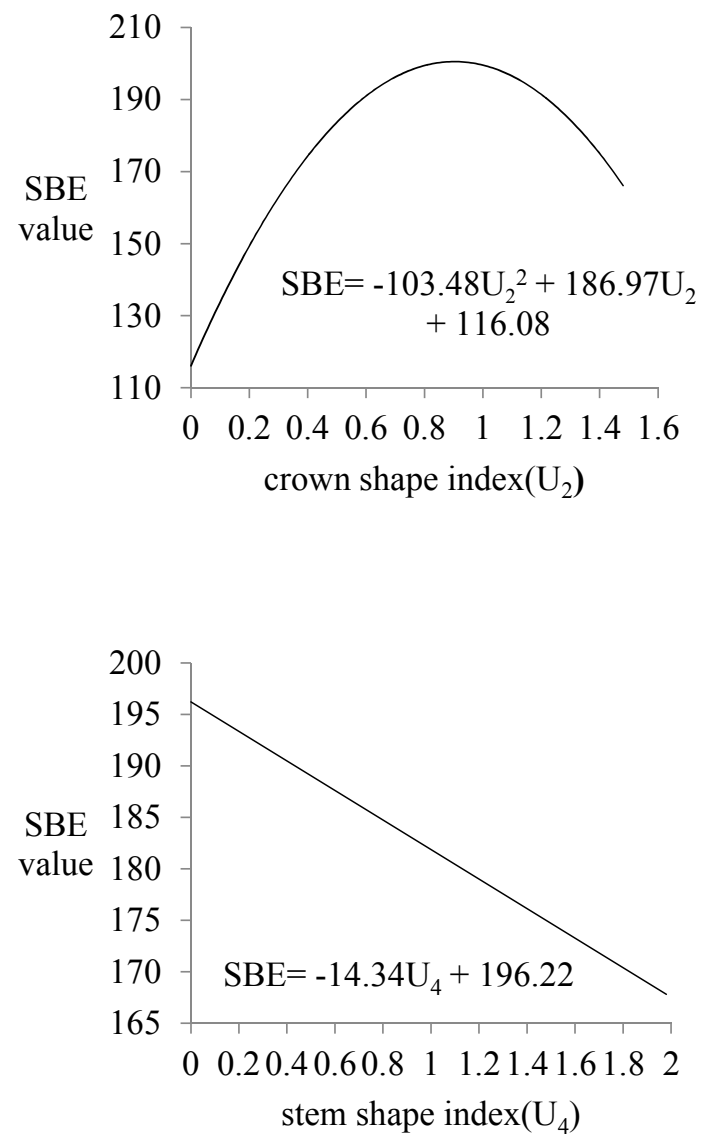

Figure 1. The relationship between four indices and SBE value change trend.

This means that in a stand forest, if enough space is available for a single tree, with its continuous growth, the quality of this tree usually develop well. However, for a single tree located in a stand forest, the effects from surrounding trees are unavoidable. There is a competitive relationship between individual tree and trees around it, for example, its crown might be overlapped by surrounding trees - this may easily lead to a disproportional ratio of tree body, and hence cause a decrease in scenic quality. The relationship between $\mathrm{SBE}$ value and $\mathrm{U}_{4}$ suggests that trees with straight trunks have high quality.

In addition, the quadratic polynomial could reflect the effect of interaction of indices with SBE grade. In this study, there is a positive correlation between SBE and the interaction of stem-crown harmony index and crown shape index, a positive correlation between SBE and crown shape index and growth index, and a negative correlation between SBE and growth index and stem shape index.

Due to the interaction between growth index and stem shape index was not significant, only one index to be set as its theoretical optimum value was necessary in making clear the influence of the interaction of other two indices on single tree's beauty quality among stem-crown harmony index, crown shape index and growth index. It can be seen from the chart of interaction between crown shape index and stem-crown harmony index (Figure 2a), while crown shape index kept stable, with the increasing of harmony index, SBE was increased. While stem-crown harmony index kept stable, with the increasing 
of crown shape index, SBE increased at first followed by a decrease. While these two both increased, SBE also increased.

In the chart of interaction between crown shape index and growth index (Figure 2b), while crown shape index kept stable with the increasing of growth index, SBE increased. While growth index kept stable with the increasing of crown shape index, SBE first increased and then decreased. While these two both increased, SBE also increased.

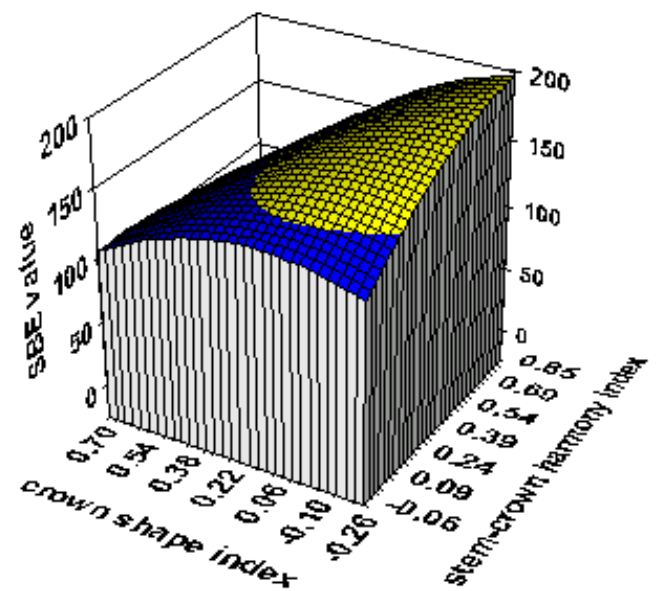

(a) effect of interaction between crown shape index and stem-crown harmony index on SBE

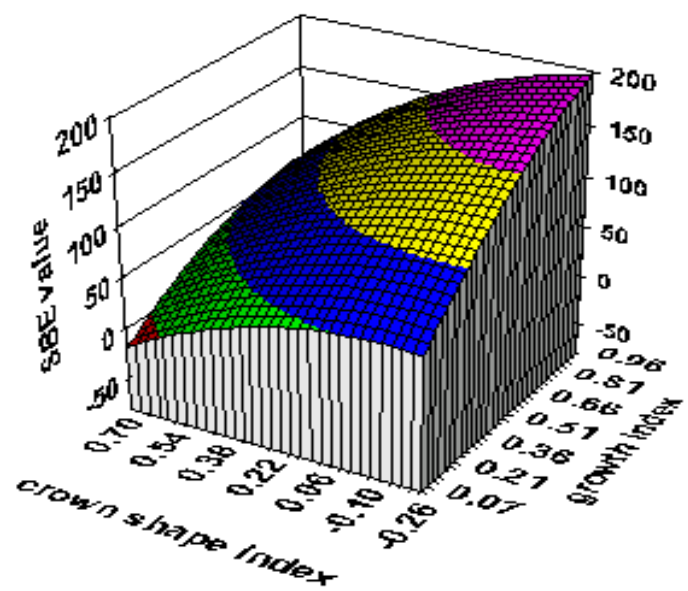

(b) effect of interaction between crown shape index and growth index on SBE

Figure 2. Effect of interaction between different indices on SBE.

\section{Discussion}

In our study, a group of parameters, including annual average increment of diameter, annual average increment of crown, crown volume, crown width/tree height ratio and crown height/tree height ratio, were found to decrease with the increasing of SBE grade. Therefore, the values of these parameters were highest when SBE was I. These results suggested that when enjoying individual trees in a scenic forest, people preferred trees with large diameter at breast height (DBH) and heavy canopies. The values of stem straight degree were found to be minimal according to peoples' preference, this indicated that peoples' favorite is tree with straight stem, secondly, is tree with a minor crook stem. These results were quite similar with previous studies $[1,13,20]$. For annual average increment of tree height (AIH) and SBE grade, previous study suggested that there was a positive relationship between them [8], which, however, in our results, was a nonlinear relationship. The different results between former studies and ours might be caused by references, which were absent in our landscape photos. Our focus was to evaluate the isolated tree, so no object was considered to provide reference during this process.

In this study, multiple regressions can be used to explain $60 \%-63 \%$ of the influence of the different factors on scenic beauty, while quadratic polynomial regressions can explain up to $66 \%$ of the influence of different factors on scenic beauty. This comparison of the four models suggested that compared with the nonlinear models, the linear models were requiring fewer or simpler input of explanatory variables, but the nonlinear could provide higher fit accuracy. Study results of Lothian (2004) indicated that 53\% of the influence of different factors on scenic beauty could be explained by the multiple regressions. This was mostly attributed to the relationship between scenic beauty and some scenic factors being 
nonlinear [9,21]. A stepwise method of multiple regressions can remove some factors to improve correlation, but could also result meanwhile in the loss of some variable information.

The disadvantage of the enter method of the quadratic polynomial model was mainly due to more explanatory variables, but the decision coefficient value was higher. The advantage of the stepwise method of the quadratic polynomial model was to reduce the number of explanatory variables input into the model, but the decision coefficient was the same as the enter method value. In addition, the relationship between indices and SBE grades in linear model is more suitable for a single tree without any others tree's influence in its growth process. However, in a standing forest, any single tree is unavoidably influenced by trees around it and finally leads to a decline in its SBE grade. Under this circumstance, quadratic polynomials can provide higher fitting precision and hence is more suitable for single trees' scenic beauty evaluations in forest stands. Therefore, the linear model fails to detect any interaction between indicators, and the employment of nonlinear models to evaluate scenic beauty is a better strategy $[22,23]$.

Currently, single landscape factor decomposition is most often adapted for an individual tree's evaluation; this affects the evaluation results due to its subjectivity. To reflect the characteristics of an individual tree objectively, quantitative indices were used in this study, this should be more scientific and rational. By virtue of nonlinear models, evaluation on single trees' scenic beauty was obtained successfully using four comprehensive indices. In addition, this study provided beneficial reference for logging while the construction of landscape beauty is considered in a stand forest. This will be useful and helpful both for practical guide and for further studies to establish more comprehensive equations in scenic beauty evaluations.

\section{Conclusions}

The high quality of landscape evaluations of individual Pinus tabulaeformis trees was established by a series of tree characteristics - large AID, full canopies, and straight stems — while some trees with a minor lean stem were also found to be of high quality. In contrast, tree height had a minor contribution to individual tree quality for a landscape.

The high correlation might suggest that there is an overlap in the nature of the two characteristics. Hence, four integrated indices, which could describe tree crown morphology, harmony between trunk and crown, and tree growth and trunk form, were constructed according to factor analysis results.

The stepwise method of a quadratic polynomial revealed the variation characteristics of SBE grade and index for individual trees, and has high fitting precision. Hence, it has been proven reliable in the prediction of scenic beauty evaluation for individual trees.

\section{Acknowledgments}

The authors gratefully acknowledge the support provided by the Ministry of Finance of People's Republic of China (Grant NO.201104051). Thanks are also extended to the experimental Xishan forest park, where good experiment fields were offered. 


\section{Author Contributions}

Bin Mao and Lan Gong contributed equally to this article. Chengyang $\mathrm{Xu}$ provided the overall guidance.

\section{Conflicts of Interest}

The authors declare no conflict of interest.

\section{References}

1. Silvennoinen, H.; Alho, J.; Kolehmainen, O.; Pukkala, T. Prediction models of landscape preferences at the forest stand level. Lands. Urban Plan. 2001, 56, 11-20.

2. Silvennoinen, H.; Pukkala, T.; Tahvanainen, L. Effect of cuttings on the scenic beauty of a tree stand. Scand. J. For. Res. 2002, 17, 263-273.

3. Daniel, T.C.; Boster, R.S. Measuring Landscape Esthetics: The Scenic Beauty Estimation Method; USDA Forest Service Research Paper: Fort Colins, CO, USA, 1976; pp. 1-66.

4. Hunziker, M.; Kienast, F. Potential impacts of changing agricultural activities on scenic beauty-A prototypical technique for automated rapid assessment. Lands. Ecol. 1999, 14, 161-176.

5. Rilbe, R.G. The aesthetics of forestry: What has empirical preference research taught us? Environ. Manag. 1989, 13, 55-74.

6. Hollenhorst, S.J.; Brock, S.M.; Freimund, W.A.; Twery, M.J. Predicting the effects of gypsymoth on near-view aesthetic preferences and recreation appeal. For. Sci. 1993, 39, 28-40.

7. Liao, W.M.; Nogami, K. Prediction of near-view scenic beauty in Artificial Stands of Hinoki. J. For. Res. 1999, 4, 93-98.

8. Lothian, A. Amenity Value of Scattered and Isolated Trees; Report to South Australian Native Vegetation Council; Unley: Adelaide, Australian, 2004.

9. Zhang, Z.D.; Xu, C.Y.; Dong, J.W.; Lian, Z.G. Impacts of canopy closure on undergrowth and landscape in scenic recreational forest a case study of Platycladus orientalis-Robinia pseudoacacia forest in Beijing. J. Chin. Urban For. 2008, 6, 10-13.

10. Bishop, I.D. Comparing regression and neural net based approaches to modeling of scenic beauty. Lands. Urban Plan. 1996, 34, 125-134.

11. Gundersen, V.S.; Frivold, L.H. Public preferences for forest structures: A review of quantitative surveys from Finland, Norway, Sweden. Urban For. Urban Green. 2008, 7, 241-258.

12. Zhang, Z.D. Quality Regulation Techniques of Scenic-Recreational Forest with Higher Scenic Beauty Value in Beijing Lower Mountainous Area; Beijing Forestry University: Beijing, China, 2010.

13. Cook, W.L. An evaluation of the aesthetic quality of forest trees. J. Leis. Res. 1972, 4, 293-302.

14. Vodak, M.C.; Roberts, P.L.; Wellman, J.D.; Buhyoff, G.J. Scenic impacts of eastern hardwood management. For. Sci. 1985, 31, 289-301.

15. Hull, B.; Buhyoff, G.; Gordell, H. Psychophysical models: An example with scenic beauty perceptions of roadside pine forests. Lands. J. 1987, 6, 113-122.

16. Paquet, J.; Belanger, L. Public acceptability thresholds of clear cutting to maintain visual quality of boreal balsam fir landscape. For. Sci. 1997, 43, 46-55. 
17. Tyrvainen, L.; Silvennoinen, H.; Kolehmainen, O. Ecological and aesthetic values in urban forest management. Urban For. Urban Green. 2003, 1, 135-149.

18. Ribe, R.G. Aesthetic perceptions of green-tree retention harvests in vista view: The interaction of cut level, retention pattern and harvest shape. Lands. Urban Plan. 2005, 73, 277-293.

19. Chen, L.Z.; Ren, J.K.; Bao, X.C.; Chen, Q.; Hu, Y.; Miao, Y.; Li, Y. Studies on the sociological characteristic and biomass of pine plantation on Xishan in Beijing. Acta Phytoecol. et Geobot. Sinaca 2010, 8, 173-180.

20. Arthur, L.M. Predicting scenic beauty of forest environments: Some empirical tests. For. Sci. 1977, 23, 151-159.

21. Liao, W.M.; Nogami, K. A fuzzy-logic-based expert system for near-view scenic beauty evaluation of Hinoki forest. J. Forest Res. 2000, 5, 139-144.

22. Shafer, E.L.; Hamilton, J.F.; Schmidt, E.A. Natural landscape preferences: A predictive model. J. Leis. Res. 1969, 1, 1-19.

23. Schroeder, H.W.; Brown, T.C. Alternative functional forms for an inventory based landscape perception model. J. Leis. Res. 1983, 15, 156-163.

(C) 2015 by the authors; licensee MDPI, Basel, Switzerland. This article is an open access article distributed under the terms and conditions of the Creative Commons Attribution license (http://creativecommons.org/licenses/by/4.0/). 